\title{
The effect of personal medical history and family history of cancer on the uptake of risk-reducing salpingo-oophorectomy
}

\author{
Jessica E. van der $\mathrm{Aa}^{1} \cdot$ Jacob P. Hoogendam $^{1} \cdot$ Els S. F. Butter ${ }^{1}$. \\ Margreet G. E. M. Ausems ${ }^{2} \cdot$ René H. M. Verheijen $^{1} \cdot$ Ronald P. Zweemer $^{1}$
}

Published online: 12 August 2015

(c) The Author(s) 2015. This article is published with open access at Springerlink.com

\begin{abstract}
Women with an increased lifetime risk of ovarian cancer are advised to undergo risk-reducing salpingo-oophorectomy (RRSO) to reduce risk of adnexal cancer. We investigated the uptake of RRSO and evaluated the influence of personal medical history of (breast) cancer, risk-reducing mastectomy (RRM) and family history of ovarian and/or breast cancer on the RRSO decision. This single center retrospective observational cohort study was performed in a tertiary multidisciplinary clinic for hereditary cancer of the University Medical Centre Utrecht, the Netherlands. Women $\geq 35$ years old with an estimated lifetime risk of ovarian cancer $\geq 10 \%$, who had completed childbearing, were eligible for RRSO. Uptake and timing of RRSO were analyzed. Influence of personal medical history and family history on RRSO decision making, were evaluated with logistic regression. The study population consisted of 218 women (45.0\% BRCA1 mutation carrier, $28.0 \%$ BRCA2 mutation carrier, $27.0 \%$ with familial susceptibility) with $87.2 \%$ RRSO uptake. The median age at RRSO was 44.5 (range 28-73) years. Of the women undergoing RRSO, $78.3 \%$ needed $\leq 3$ consultations to reach this decision. Multivariable analysis showed a significant difference in RRSO uptake for women with a history of RRM [OR $3.6695 \%$ CI (1.12-11.98)], but no significant difference in women with a history of breast
\end{abstract}

Ronald P. Zweemer

r.zweemer@umcutrecht.nl

1 Department of Gynaecological Oncology, UMC Utrecht Cancer Center, Heidelberglaan 100, 3584 CX Utrecht, The Netherlands

2 Department of Medical Genetics, University Medical Center Utrecht, Heidelberglaan 100, 3584 CX Utrecht, The Netherlands cancer [OR $1.3895 \% \mathrm{CI}(0.50-3.79)]$, nor with a family history of ovarian and/or breast cancer [OR $1.1095 \%$ CI (0.44-2.76)]. We conclude that RRSO counseling, without the alternative of screening, is effective. The uptake is increased in women with a history of RRM.

Keywords Hereditary ovarian cancer - BRCA1 . BRCA2 - Risk-reducing salpingo-oophorectomy · Prophylactic surgery uptake

\section{Introduction}

Women carrying a BRCA1 or BRCA2 gene mutation have a life time risk of developing ovarian cancer of 31-58.9 and 6-34.5\% respectively [1-5]. Risk-reducing salpingooophorectomy (RRSO) has been associated with a risk reduction of $85-96 \%$ for ovarian, fallopian tube and peritoneal cancer [6-9]. A meta-analysis by Marchetti et al. (2014), showed a hazard ratio of 0.19 (95\% CI 0.13-0.27) for the development of ovarian cancer in BRCA1/2 mutation carriers up to six years after RRSO [10]. A large metaanalysis by Rebbeck et al. [11] showed a hazard ratio of 0.21 (95\% CI 0.12-0.39) for the development of ovarian or breast cancer, up to five years after RRSO. Risk reduction of breast cancer after RRSO was estimated to be 53-72\% in BRCA1/2 mutation carriers in several studies [6-9]. A recent Dutch cohort study found no evidence for a risk reduction of breast cancer risk in BRCA1/2 mutation carriers after RRSO [hazard ratio $1.09 \quad(95 \%$ CI $0.67-1.77)]$ and stated that previous data may have overestimated the risk reduction because of bias [12].

Screening for ovarian cancer by determining CA125 protein serum levels and performing transvaginal ultrasonography, has proven to be neither reliable, nor 
beneficial in reducing the risk of ovarian cancer, nor does it improve survival [13-19]. Therefore, RRSO is the only scientifically proven strategy to reduce the risk of developing ovarian and fallopian tube cancer and it is recommended to women with an increased lifetime risk [10, 11].

The Multidisciplinary Hereditary Cancer Clinic (MHCC) of the UMC Utrecht aims to counsel and treat women at increased lifetime risk of developing ovarian cancer. This encompasses BRCA1/2 mutation carriers and women with familial susceptibility to ovarian cancer, which is determined by having a pedigree-based estimated lifetime risk of $\geq 10 \%$ [20]. When over 35 years of age and having completed childbearing, these women become eligible for RRSO [21]. During RRSO counseling, the surgical risks as well as the benefits and indications for Hormonal Replacement Therapy (HRT) after surgery, are outlined. Screening is explicitly not offered as an alternative to RRSO. Psychosocial support is routinely offered in the process of decision making.

Reported RRSO uptake in the literature varies from 10.9 to $75 \%$ [22-34]. With our approach, we expect a high RRSO uptake, since undergoing the surgery is the only risk-reducing strategy.

There are demographic, medical and psychosocial factors that affect the decision making to undergo risk-reducing surgery, including age, parity, menopausal status, ethnicity, education level, idea of perceived risk, level of anxiety or distress, etcetera [22, 23, 25-28, 30, 32-35]. Since BRCA1/2 mutation status and familial susceptibility to ovarian cancer are familial conditions that concern close relatives, it is assumed that decision making may be influenced by personal experience and family perspectives or experience with cancer within the family. Several studies support this by showing an increase of RRSO uptake with a more positive family history of breast and/or ovarian cancer [23, 27, 29, 33]. However, others do not report this [28].

Here, we explore the effect of a personal medical history of breast cancer and risk-reducing mastectomy (RRM) as well as family history of ovarian and/or breast cancer in the decision making of undergoing RRSO for women with an increased lifetime risk of ovarian cancer. Secondly, we determined how many consultations were needed for women to decide to undergo RRSO. This insight is of importance, to provide personally appropriate counseling to every patient.

\section{Methods}

\section{MHCC and counseling}

In this single center retrospective cohort study, we identified all women who visited the MHCC from January 2011 through June 2013. Genetic testing and pedigree-based risk assessment were performed by the medical genetics department. Carriers of a BRCA1 mutation are explained to have a lifetime risk of ovarian cancer of 30-60\% and BRCA2 mutation carriers of 5-20\%. RRSO is recommended from age 35 years onwards (BRCA1 carrier) or from 40 years onwards (BRCA2 carrier). Women with a positive family history, but in whom genetic testing in an affected relative could not be performed, or could not identify a BRCA mutation (e.g. due to uninformative test result), were defined as women with a familial susceptibility to ovarian cancer. They are advised to undergo RRSO when the estimated lifetime risk is $\geq 10 \%$.

In adherence to the Dutch guideline for treatment of hereditary ovarian cancer, women were considered eligible for RRSO with an estimated lifetime risk $\geq 10 \%$ and if they were $\geq 35$ years of age and had completed childbearing [18]. They received counseling for RRSO from a gynecologic oncologist and a nurse specialized in familial cancer care. Counseling was aimed at informing patients about the risks of the surgery, the induction of menopausal status by the surgery and indications for HRT, the medical and psychosocial support available, the risks of developing ovarian and fallopian tube cancer and the reduction of this risk by undergoing RRSO.

\section{Study population}

The study population consists of all women who received counseling for RRSO, based on the criteria described previously. Women who had completed childbearing at $<35$ years of age and had received counseling for RRSO were included too.

Women previously diagnosed with ovarian cancer, carriers of a mutation in one of the MMR genes (predisposing to Lynch syndrome), women with increased risk of breast cancer or other non-breast and ovarian related hereditary tumors only, were excluded.

\section{Statistical analysis}

Statistical analyses were carried out using the 'Statistical Package for the Social Sciences' version 21.0 (SPSS, International Business Machines, New York, United States). Comparison of categorical variables was performed by Chi square testing. The Mann-Whitney $U$ test was used for count data and continuous variables that were not normally distributed. A $p$ value of $<0.05$ was considered statistically significant.

Uni- and multivariable logistic regression, producing odds ratios (OR), were used to model the explanatory variables against the binary RRSO decision. Explanatory variables of interest included the effect of personal medical 
history of breast cancer, any malignancy (excluding all non-melanoma skin malignancies) and RRM. Furthermore, family history of ovarian and/or breast cancer were analyzed according to the first or second/third degree in which they occurred. Multiple imputations $(\mathrm{m}=10)$ were used to correct randomly missing values.

During the multivariable analysis, explanatory variables were adjusted for mutation status, age, parity and menopausal status, since these have been identified as significant factors of influence in previous studies [22, 23, 27-30, 3234].

\section{Results}

\section{Study population}

We identified 218 women who were considered eligible for undergoing RRSO. As shown in Table 1, the majority carried a BRCA1 or BRCA2 mutation (72.9\%).

In total, 190 women opted for RRSO, resulting in an uptake of $87.2 \%$. Uptake was higher in BRCA1/2 mutation carriers than in women with familial susceptibility to ovarian cancer (90.6 and $78.0 \%$ respectively).

Median age at RRSO was 44.5 (range 28-73). Median ages at RRSO for BRCA1 mutation carriers, BRCA2 mutation carriers and women with familial susceptibility were 42 (range 30-63), 47 (range 28-73) and 48 years (range 31-65) respectively.

\section{Number of consultations}

We registered the number of consultations women had had with the gynecologic oncologist before they decided to undergo RRSO. It showed that $57.4 \%$ of the women who eventually underwent RRSO, had decided so at the first consultation with the gynecologic oncologist or the specialized nurse. An additional $11.1 \%$ had decided so by the second consultation and an additional $5.3 \%$ had made this decision by the third consultation. The remaining $26.2 \%$ needed four or more consultations to make the decision.

Women with 1st degree relatives who had breast cancer needed significantly less consultations to decide for RRSO, this in contrast to having 1st degree relatives with ovarian cancer. See Table 2 for the univariable analysis. After multivariable adjustment, only a 1st degree relative with breast cancer remained as a significant factor ( $p$ 0.01) with $1.51(95 \% \mathrm{CI}$ 0.32-2.70) less consultations before the RRSO decision.

\section{Personal and medical history}

Table 3 shows the outcomes of univariable and multivariable analyses of RRSO uptake in women with family
Table 1 Baseline characteristics of study-population $n=218$

\begin{tabular}{|c|c|}
\hline \multicolumn{2}{|l|}{ Mutation status, n (\%) } \\
\hline BRCA1 & $98(45.0 \%)$ \\
\hline $\mathrm{BRCA} 2$ & $61(28.0 \%)$ \\
\hline Familial susceptibility & $59(27.0 \%)$ \\
\hline \multicolumn{2}{|l|}{ Age at first presentation } \\
\hline Median (range), years & $43(27-77)$ \\
\hline Mean (Standard deviation), years & $44.63( \pm 9.37)$ \\
\hline \multicolumn{2}{|l|}{ Menopausal status at first presentation } \\
\hline Premenopausal, n (\%) & $126(57.8 \%)$ \\
\hline Postmenopausal, n (\%) & $70(32.1 \%)$ \\
\hline Unknown, n (\%) & $22(10.1 \%)$ \\
\hline \multicolumn{2}{|l|}{ Parity, n (\%) } \\
\hline $0, \mathrm{n}(\%)$ & $40(18.3 \%)$ \\
\hline $1, \mathrm{n}(\%)$ & $22(10.1 \%)$ \\
\hline $2, \mathrm{n}(\%)$ & $88(40.4 \%)$ \\
\hline$>2, \mathrm{n}(\%)$ & $46(21.1 \%)$ \\
\hline Unknown, n (\%) & $22(10.1 \%)$ \\
\hline \multicolumn{2}{|l|}{ Medical history } \\
\hline No malignancy, n (\%) & $143(65.6 \%)$ \\
\hline Breast cancer, $\mathrm{n}(\%)$ & $70(32.1 \%)$ \\
\hline Other malignancy, n (\%) & $5(2.3 \%)$ \\
\hline \multicolumn{2}{|l|}{ Family history } \\
\hline Positive for ovarian cancer, $\mathrm{n}(\%)$ & $102(46.8 \%)$ \\
\hline Positive for breast cancer, $\mathrm{n}(\%)$ & $140(64.2 \%)$ \\
\hline Positive for breast and ovarian cancer, n (\%) & $76(34.9 \%)$ \\
\hline Unknown, n (\%) & $51(23.4 \%)$ \\
\hline \multicolumn{2}{|l|}{$\mathrm{RRSO}^{\mathrm{a}}$ uptake } \\
\hline Yes, n $(\%)$ & $190(87.2 \%)$ \\
\hline No, n $(\%)$ & $28(12.8 \%)$ \\
\hline \multicolumn{2}{|l|}{ Age at $\operatorname{RRSO}^{a}(n=186)$} \\
\hline Median (range), years & $44.5(28-73)$ \\
\hline Mean (standard deviation), years & $46.32( \pm 8.24)$ \\
\hline \multicolumn{2}{|l|}{$\mathrm{RRM}^{\mathrm{b}}$ uptake } \\
\hline Yes, n $(\%)$ & $107(49.1 \%)$ \\
\hline No, n $(\%)$ & $93(42.7 \%)$ \\
\hline Missing, n (\%) & $18(8.3 \%)$ \\
\hline
\end{tabular}

history of ovarian and/or breast cancer or a personal history of (breast) cancer.

Women who had previously been diagnosed with breast cancer or any other type of cancer (excluding all non-melanoma skin malignancies), did not have significantly increased odds of undergoing a RRSO [OR 1.38; $95 \%$ confidence interval (CI) (0.50-3.79) and OR 1.60; $95 \% \mathrm{CI}$ (0.59-4.37) respectively]. Women who had undergone RRM were more likely to undergo RRSO, with an odds ratio of $3.66 ; 95 \%$ CI (1.12-11.98) in multivariable analysis. 
Table 2 Number of consultations needed to decide for RRSO relative to personal and family history $(\mathrm{n}=190)$

\begin{tabular}{|c|c|c|c|}
\hline & \multicolumn{2}{|c|}{ Mean \pm standard deviation number of consultations ${ }^{\mathrm{a}}$} & \multirow[t]{2}{*}{$p$ value $^{\mathrm{b}}$} \\
\hline & Absent & Present & \\
\hline Breast cancer in personal medical history & $2.29 \pm 3.19$ & $2.90 \pm 3.02$ & 0.51 \\
\hline Any malignancy in personal medical history ${ }^{\mathrm{c}}$ & $2.35 \pm 3.24$ & $2.73 \pm 2.93$ & 0.67 \\
\hline $\mathrm{RRM}^{\mathrm{d}}$ in personal medical history & $2.11 \pm 2.54$ & $3.10 \pm 3.90$ & 0.38 \\
\hline Ovarian cancer in 1 st degree relative & $2.19 \pm 2.80$ & $2.96 \pm 3.61$ & 0.02 \\
\hline Ovarian cancer in 2 nd or 3 rd degree relative & $2.30 \pm 2.90$ & $3.14 \pm 3.88$ & 0.33 \\
\hline Breast cancer in 1 st degree relative & $3.09 \pm 3.82$ & $1.90 \pm 2.20$ & $<0.01$ \\
\hline Breast cancer in 2 nd or 3 rd degree relative & $2.19 \pm 2.46$ & $3.02 \pm 4.11$ & 0.06 \\
\hline
\end{tabular}

Statistically significant $p$ values are presented in bold

a While 'number of consultations' follows a Poisson distribution, results are deliberately presented in means and standard deviations whereas medians and ranges (in integer values) would obscure the subtle differences between groups

${ }^{\mathrm{b}}$ Based on the non-parametric Mann-Whitney $U$ test

c Excludes all non-melanoma skin malignancies

${ }^{\mathrm{d}}$ Risk-reducing mastectomy

Table 3 Personal and family history and its effect on uptake of risk-reducing salpingo-oophorectomy

\begin{tabular}{|c|c|c|c|c|c|}
\hline & $\begin{array}{l}\mathrm{RRSO}^{\mathrm{a}} \text { uptake } \\
(\%)\end{array}$ & $\begin{array}{l}\text { Univariable } \\
\mathrm{OR}^{\mathrm{b}}\end{array}$ & $95 \% \mathrm{CI}^{\mathrm{c}}$ & $\begin{array}{l}\text { Multivariable } \\
\text { OR }^{\mathrm{d}}\end{array}$ & $95 \% \mathrm{CI}^{\mathrm{c}}$ \\
\hline Breast cancer in personal medical history & 91.4 & 1.86 & $0.72-4.82$ & 1.38 & $0.50-3.79$ \\
\hline Any malignancy in personal medical history ${ }^{\mathrm{e}}$ & 92.0 & 2.09 & $0.81-5.41$ & 1.60 & $0.59-4.37$ \\
\hline $\mathrm{RRM}^{\mathrm{f}}$ in personal medical history & 94.7 & 3.59 & $1.20-10.73$ & 3.66 & 1.12-11.98 \\
\hline Ovarian cancer in 1 st degree relative & 84.3 & 0.52 & $0.21-1.27$ & 0.61 & $0.23-1.62$ \\
\hline Ovarian cancer in 2 nd or 3 rd degree relative & 90.0 & 1.27 & $0.40-4.05$ & 1.30 & $0.37-4.57$ \\
\hline Breast cancer in 1 st degree relative & 88.8 & 1.16 & $0.46-2.91$ & 0.85 & $0.31-2.33$ \\
\hline Breast cancer in $2 \mathrm{nd}$ or $3 \mathrm{rd}$ degree relative & 88.3 & 1.13 & $0.46-2.80$ & 1.30 & $0.49-3.44$ \\
\hline $\begin{array}{l}\text { Ovarian and breast cancer in 1st, } 2 \text { nd or } 3 \text { rd degree } \\
\text { relative }\end{array}$ & 86.8 & 1.02 & $0.42-2.47$ & 1.10 & $0.44-2.76$ \\
\hline
\end{tabular}

Statistically significant odds ratios are presented in bold

a Risk-reducing salpingo-oophorectomy

b Odds ratio

${ }^{c}$ Confidence interval

d Adjusted for mutation status, age, parity and menopausal status

e Excludes all non-melanoma skin malignancies

${ }^{\mathrm{f}}$ Risk-reducing mastectomy

No significant increased odds of undergoing a RRSO were identified if there was a first or a second/third degree relative with a history of ovarian cancer [OR $0.61 ; 95 \% \mathrm{CI}$ (0.23-1.62) and OR 1.30; $95 \%$ CI (0.37-4.57) respectively]. This also accounted for women with a first or second/third degree relative with a history of breast cancer [OR $0.85 ; 95 \%$ CI $(0.31-2.33)$ and OR $1.30 ; 95 \%$ CI (0.49-3.44) respectively]. Family history of ovarian and/or breast cancer evaluated altogether also showed no significant increased odds for undergoing RRSO [OR 1.10; $95 \%$ CI (0.44-2.76)].

\section{Discussion}

We show that RRSO uptake is high after counseling and that only few consultations at the gynecologist are needed, to decide to undergo RRSO.

Secondly, women with a personal medical history of breast cancer do not seem to be more likely to undergo RRSO, than those without. This also accounts for women with a family history of ovarian and/or breast cancer.

Reported RRSO uptake in the literature varies from 10.9 to $75 \%$ [22-34]. In comparison, RRSO uptake in this 
study is relatively high. An explanation for this difference is that in most studies, screening for ovarian cancer is offered as an alternative to undergoing RRSO [23, 26-29, 32-34], even though in the meantime it had sufficiently been shown that this was not effective in reducing ovarian cancer mortality [13-19].

It has been published that RRSO uptake is higher in women with a personal medical history of breast cancer $[22,23,27,29]$. But only two studies could support this with significant results in multivariable analyses [27, 29]. In two other studies, RRSO uptake was even lower in women with a medical history of breast cancer [28, 32].

In several studies, RRM in personal medical history also seemed to have an influence, showing positive odds ratios in univariable analyses [7, 22, 23, 28].

Family history of ovarian and/or breast cancer were thought to be factors of influence, as some studies conclude $[23,27,30,33]$, although not all analyses were multivariable with adjustment for known factors of influence [27, 33].

A limitation of this study is that information bias might have occurred because of the study design. Although not all possible factors of influence in the decision making of undergoing RRSO (i.e. demographic factors) could be evaluated, for lack of available information. Detailed information on family history was not present for every patient, but it was collected as thoroughly as possible by standardized questioning by the experts.

Our findings are likely influenced by the method of counseling performed and particularly the fact that screening was not offered. Therefore, results of this study may not be extended towards situations where alternative strategies such as screening are offered. However, our results do indicate that a protocol based solely on RRSO counseling, without the alternative option of screening, is effective in establishing a high uptake of RRSO in women with an increased lifetime risk of ovarian cancer. This protocol can be useful in a variety of health-care systems given that most women who ultimately decide for RRSO needed 3 or less counseling sessions. We consider a multidisciplinary approach by a gynecologic oncologist, clinical geneticist and nurse specialist, specialized in familial cancer care, pivotal in this counseling practice.

Future studies may focus on validating the current results, as well as investigating other possible factors of influence (e.g. psychological), possibly within the context of a qualitative study. Especially the subgroup who needed $>3$ consultations in the RRSO decision making process is of interest with respect to their considerations. Such an analysis may identify opportunities for improving and individualizing the counseling practice.

In conclusion, the majority $(87.2 \%)$ of the women carrying a BRCA mutation or having familial susceptibility to ovarian cancer, who visited our clinic, where screening is not offered, opted for RRSO. This decision is made relatively quick; the majority decided after the first consultation with the gynecologist. This approach is therefore likely to be effective in reducing ovarian cancer related mortality in this high risk population. Personal medical history of (breast) cancer was not found to significantly affect the decision to undergo RRSO, though women who had undergone RRM were more likely to opt for RRSO. Also, patients with 1st degree relatives who had breast cancer needed significantly less consultations to decide for RRSO.

\section{Compliance with ethical standards}

Conflict of interest All authors declare to have no conflict of interest relevant to the presented research or manuscript.

Open Access This article is distributed under the terms of the Creative Commons Attribution 4.0 International License (http://creative commons.org/licenses/by/4.0/), which permits unrestricted use, distribution, and reproduction in any medium, provided you give appropriate credit to the original author(s) and the source, provide a link to the Creative Commons license, and indicate if changes were made.

\section{References}

1. Antoniou A, Pharoah PD, Narod S, Risch HA et al (2003) Average risks of breast and ovarian cancer associated with BRCA1 or BRCA2 mutations detected in case Series unselected for family history: a combined analysis of 22 studies. Am J Hum Genet 72(5):1117-1130

2. Brohet RM, Velthuizen ME, Hogervorst FBL, Meijers-Heijboer HEJ et al (2014) Breast and ovarian cancer risks in a large series of clinically ascertained families with a high proportion of BRCA1 and BRCA2 Dutch founder mutations. J Med Genet 51:98-107

3. Couch FJ, Gaudet MM, Antoniou AC, Ramus SJ et al (2012) Consortium of Investigators of Modifiers of BRCA1/2. Common variants at the 19p13.1 and ZNF365 loci are associated with ER subtypes of breast cancer and ovarian cancer risk in BRCA1 and BRCA2 mutation carriers. Cancer Epidemiol Biomark Prev 21(4):645-657

4. King MC, Marks JH (2003) Mandell JB; New York Breast Cancer Study Group. Breast and ovarian cancer risks due to inherited mutations in BRCA1 and BRCA2. Science 302(5645):643-646

5. van der Kolk DM, de Bock GH, Leegte BK, Schaapveld M, Mourits MJ, de Vries J, van der Hout AH, Oosterwijk JC (2010) Penetrance of breast cancer, ovarian cancer and contralateral breast cancer in BRCA1 and BRCA2 families: high cancer incidence at older age. Breast Cancer Res Treat 124(3):643-651

6. Finch A, Beiner M, Lubinski J, Lynch HT, Moller P, Rosen B, Murphy J, Ghadirian P, Friedman E, Foulkes WD, Kim-Sing C, Wagner T, Tung N, Couch F, Stoppa-Lyonnet D, Ainsworth P, Daly M, Pasini B, Gershoni-Baruch R, Eng C, Olopade OI, McLennan J, Karlan B, Weitzel J, Sun P (2006) Narod SA; Hereditary Ovarian Cancer Clinical Study Group. Salpingooophorectomy and the risk of ovarian, fallopian tube, and peritoneal cancers in women with a BRCA1 or BRCA2 Mutation. JAMA 296(2):185-192 
7. Kauff ND, Satagopan JM, Robson ME, Scheuer L, Hensley M, Hudis CA, Ellis NA, Boyd J, Borgen PI, Barakat RR, Norton L, Castiel M, Nafa K, Offit K (2002) Risk-reducing salpingooophorectomy in women with a BRCA1 or BRCA2 mutation. N Engl J Med 346(21):1609-1615

8. Kauff ND, Domchek SM, Friebel TM, Robson ME, Lee J, Garber JE, Isaacs C, Evans DG, Lynch H, Eeles RA, Neuhausen SL, Daly MB, Matloff E, Blum JL, Sabbatini P, Barakat RR, Hudis C, Norton L, Offit K, Rebbeck TR (2008) Risk-reducing salpingooophorectomy for the prevention of BRCA1- and BRCA2-associated breast and gynecologic cancer: a multicenter, prospective study. J Clin Oncol 26(8):1331-1337

9. Rebbeck TR, Lynch HT, Neuhausen SL, Narod SA (2002) Van't Veer L, Garber JE, Evans G, Isaacs C, Daly MB, Matloff E, Olopade OI, Weber BL; Prevention and Observation of Surgical End Points Study Group. Prophylactic oophorectomy in carriers of BRCA1 or BRCA2 mutations. N Engl J Med 346(21): 1616-1622

10. Marchetti C, De Felice F, Palaia I, Perniola G, Musella A, Musio D, Muzii L, Tombolini V, Panici PB (2014) Risk-reducing salpingo-oophorectomy: a meta-analysis on impact on ovarian cancer risk and all cause mortality in BRCA 1 and BRCA 2 mutation carriers. BMC Women's Health 14:150

11. Rebbeck TR, Kauff ND, Domchek SM (2009) Meta-analysis of risk reduction estimates associated with risk-reducing salpingooophorectomy in BRCA1 or BRCA2 mutation carriers. J Natl Cancer Inst 101(2):80-87

12. Heemskerk-Gerritsen BA, Seynaeve C, van Asperen CJ, Ausems MG, Collée JM, van Doorn HC, GomezGarcia EB, Kets CM, van Leeuwen FE, Meijers-Heijboer HE, Mourits MJ, van Os TA, Vasen HF, Verhoef S, Rookus MA, Hooning MJ (2015) Breast cancer risk after salpingo-oophorectomy in healthy BRCA1/2 mutation carriers: revisiting the evidence for risk reduction. J Natl Cancer Inst 107(5):812-822

13. Gaarenstroom KN, van der Hiel B, Tollenaar RA, Vink GR, Jansen FW, van Asperen CJ et al (2006) Efficacy of screening women at high risk of hereditary ovarian cancer: results of an 11-year cohort study. Int J Gynecol Cancer 16(Suppl 1):54-59

14. Hermsen BB, Olivier RI, Verheijen RH, van Beurden M, de Hullu JA, Massuger LF, Burger CW, Brekelmans CT, Mourits MJ, de Bock GH, Gaarenstroom KN, van Boven HH, Mooij TM, Rookus MA (2007) No efficacy of annual gynaecological screening in BRCA1/2 mutation carriers; an observational follow-up study. Br J Cancer 96(9):1335-1342

15. Meeuwissen PA, Seynaeve C, Brekelmans CT, Meijers-Heijboer HJ, Klijn JG, Burger CW (2005) Outcome of surveillance and prophylactic salpingo-oophorectomy in asymptomatic women at high risk for ovarian cancer. Gynecol Oncol 97:476-482

16. Oei AL, Massuger LF, Bulten J, Ligtenberg MJ, Hoogerbrugge N, de Hullu JA (2006) Surveillance of women at high risk for hereditary ovarian cancer is inefficient. $\mathrm{Br} \mathrm{J}$ Cancer 94(6): 814-819

17. Olivier RI, Lubsen-Brandsma MA, Verhoef S, van Beurden M (2006) CA125 and transvaginal ultrasound monitoring in highrisk women cannot prevent the diagnosis of advanced ovarian cancer. Gynecol Oncol 100(1):20-26

18. Vasen HF, Tesfay E, Boonstra H, Mourits MJ, Rutgers E, Verheijen R et al (2005) Early detection of breast and ovarian cancer in families with BRCA mutations. Eur J Cancer 41:549-554

19. van der Velde NM, Mourits MJ, Arts HJ, de Vries J, Leegte BK, Dijkhuis G, Oosterwijk JC, de Bock GH (2009) Time to stop ovarian cancer screening in BRCA1/2 mutation carriers. Int $\mathbf{J}$ Cancer 124(4):919-923

20. de Hullu JA, Kets CM, Massuger LF, Ligtenberg ML, van Ham MA, Hoogerbrugge N (2010) Familiaire belasting voor ovariumcarcinoom: beleid. Ned Tijdschr Geneeskd 154:A2392
21. Vasen HFA, Hes FJ (2010) Richtlijnen voor diagnostiek en preventie. STOET \& WKO, Leiden ( $4^{\mathrm{e}}$ druk)

22. Beattie MS, Crawford B, Lin F, Vittinghoff E, Ziegler J (2009) Uptake, time course and predictors of risk-reducing surgeries in BRCA carriers. Genet Test Mol Biomark 13(1):51-56

23. Bradbury AR, Ibe CN, Dignam JJ, Cummings SA, Verp M, White MA, Artioli G, Dudlicek L, Olopade OI (2008) Uptake and timing of bilateral prophylactic salpingo-oophorectomy among BRCA1 and BRCA2 mutation carriers. Genet Med 10(3):161-166

24. Chai X, Friebel TM, Singer CF, Evans DG, Lynch HT, Isaacs JE et al (2014) Use of risk-reducing surgeries in a prospective cohort of 1499 BRCA1 and BRCA2 mutation carriers. Breast Cancer Res Treat 148:397-406

25. Evans DG, Lalloo F, Ashcroft L, Shenton A, Clancy T, Baildam AD, Brain A, Hopwood P, Howell A (2009) Uptake of riskreducing surgery in unaffected women at high risk of breast and ovarian cancer is risk, age, and time dependent. Cancer Epidemiol Biomark Prev 18(8):2318-2324

26. Garcia C, Wendt J, Lyon L, Jones J, Littell RD, Armstrong MA, Raine-Bennett T, Powell CB (2014) Risk management options elected by women after testing positive for a BRCA mutation. Gynecol Oncol 132(2):428-433

27. Kim D, Kang E, Hwang E, Sun Y, Hwang Y, Yom CK, Kim K, No JH, Kim YB, Kim SW (2013) Factors affecting the decision to undergo risk-reducing salpingo-oophorectomy among women with BRCA gene mutation. Fam Cancer 12(4):621-628

28. Madalinska JB, van Beurden M, Bleiker EM, Valdimarsdottir HB, Lubsen-Brandsma L, Massuger LF, Mourits MJ, Gaarenstroom KN, van Dorst EB, van der Putten $\mathrm{H}$, Boonstra $\mathrm{H}$, Aaronson NK (2007) Predictors of prophylactic bilateral salpingo-oophorectomy compared with gynecologic screening use in BRCA1/2 mutation carriers. J Clin Oncol 25(3):301-307

29. Manchanda R, Burnell M, Abdelraheim A, Johnson M, Sharma A, Benjamin E, Brunell C, Saridogan E, Gessler S, Oram D, Side L, Rosenthal AN, Jacobs I, Menon U (2012) Factors influencing uptake and timing of risk reducing salpingo-oophorectomy in women at risk of familial ovarian cancer: a competing risk time to event analysis. BJOG 119(5):527-536

30. Meiser B, Price MA, Butow PN, Karatas J, Wilson J, Heiniger L, Baylock B, Charles M, McLachlan SA, Phillips KA (2013) Psychosocial factors and uptake of risk-reducing salpingooophorectomy in women at high risk for ovarian cancer. Fam Cancer 12(1):101-109

31. Rhiem K, Foth D, Wappenschmidt B, Gevensleben H, Buttner R, Ulrich U, Schmutzler RK (2011) Risk-reducing salpingooophorectomy in BRCA1 and BRCA2 mutation carriers. Arch Gynecol Obstet 283:623-627

32. Sidon L, Ingham S, Clancy T, Clayton R, Clarke A, Jones EA, Lalloo F, Evans DG (2012) Uptake of risk-reducing salpingooophorectomy in women carrying a BRCA1 or BRCA2 mutation: evidence for lower uptake in women affected by breast cancer and older women. Br J Cancer 106(4):775-779

33. Singh K, Lester J, Karlan B et al (2013) Impact of family history on choosing risk-reducing surgery among BRCA mutation carriers. Am J Obstet Gynecol 208:329.e1-329.e6

34. Skytte AB, Gerdes AM, Andersen MK, Sunde L, Brøndum-Nielsen K, Waldstrøm M, Kølvraa S, Crüger D (2010) Risk-reducing mastectomy and salpingo-oophorectomy in unaffected BRCA mutation carriers: uptake and timing. Clin Genet 77(4):342-349

35. Madalinska JB, Hollenstein J, Bleiker E, van Beurden M, Valdimarsdottir HB, Massuger LF, Gaarenstroom KN, Mourits MJ, Verheijen RH, van Dorst EB, van der Putten $\mathrm{H}$, van der Velden K, Boonstra H, Aaronson NK (2005) Quality-of-life effects of prophylactic salpingo-oophorectomy versus gynaecologic screening among women at increased risk of hereditary ovarian cancer. J Clin Oncol 23:6890-6898 